\title{
PAISAGENS DA COMPREENSÃO: CONTRIBUIÇÕES DA HERMENÊUTICA E DA FENOMENOLOGIA PARA UMA EPISTEMOLOGIA DA EDUCAÇÃO AMBIENTAL
}

\author{
Isabel Cristina de Moura Carvalho* \\ MAURO GRÜN* \\ Maria Rita AvanZi ${ }^{* *+}$
}

\begin{abstract}
RESUMO: O artigo discute a questão da compreensão desde a experiência da obra de arte e do jogo como modelos da compreensão em Gadamer. Desde esta perspectiva, tematiza a abertura e o engajamento como aspectos constitutivos da experiência de compreensão do mundo na perspectiva da hermenêutica e explora suas consequências em termos do pertencimento ao ambiente, no sentido de um ambiente-mundo. Propóe, em continuidade com esta abordagem, a noção de paisagem como engajamento e pertencimento ao "corpo do mundo". Para fundamentar este conceito de paisagem, são acionadas a antropologia ecológica de Tim Ingold e a fenomenologia de Merleau-Ponty, que sugerem, cada uma a seu modo, a continuidade na relação humanos/não-humanos. Ao final, são apontados desdobramentos de uma epistemologia compreensiva para a educação ambiental a partir da reflexão sobre uma intervenção educativa de pesquisa-ação em educação ambiental no Vale do Ribeira.

Palavras-chave: Experiência. Hermenêutica. Fenomenologia. Paisagem.
\end{abstract}

Doutora em Educação e professora da Pontifícia Universidade Católica do Rio Grande do Sul (PUC-RS).E-mail: isabel.carvalho@pq.cnpq.br

** Doutor em Educação e professor do Centro Universitário La Salle (Canoas, RS).

E-mail:mgrun@uol.com.br

*** Doutora em Educação e professora da Universidade de Brasília (UNB).

E-mail: rioavanzi@hotmail.com

Cad. Cedes, Campinas, vol. 29, n. 77, p. 99-115, jan./abr. 2009

Disponível em <http://www.cedes.unicamp.br> 
Paisagens da compreensão: contribuiçôes da hermenêutica e da fenomenologia...

UNDERSTANDING LANDSCAPE: CONTRIBUTIONS FROM HERMENEUTIC AND PHENOMENOLOGY TOWARD AN EPISTEMOLOGY OF ENVIRONMENTAL EDUCATION

ABSTRACT: This article argues the question of the understanding since the experience of the work of art and the game as models of the understanding in Gadamer. Since this perspective, discuss the opening and the engagement as constituent aspects of the experience of understanding of the world in the perspective of the hermeneutics and explores its consequences in terms of the belonging to the environment, in the sense of a environmentworld. It considers, in continuity with this perspective, the notion of landscape as engagement and belonging to the "body of the world". In order to propose this concept of landscape we use the ecological anthropology of Tim Ingold and the phenomenology of Merleau-Ponty who suggest, each one in its way, the continuity in the relation human and no human beings. Finally, a comprehensive epistemology is pointed out from the reflection on an intervention of research-action in environmental education in the "Vale do Ribeira".

Key words: Experience. Hermeneutic. Phenomenology. Landscape.

\section{Introdução}

$\mathcal{E}$

ste artigo reune algumas de nossas reflexões como educadores e pesquisadores em torno da questão da experiência de compreensão e suas consequências para a educação ambiental. Esta é uma questão que ganhou centralidade em tradiçōes filosóficas como a hermenêutica e a fenomenologia. Em sintonia com estas abordagens, tomamos a noção de compreensão não em seu sentido cognitivo como habilidade linguística de entender, explicar ou ainda expressar certa experiência humana do mundo, mas como lugar constitutivo desta experiência. A compreensão, nesse sentido, é o modo de estar no mundo. ${ }^{1}$ A marca deste encontro compreensivo é a conversação ou o diálogo em que se é interpelado pelo outro, num exercício de alteridade que torna possível a hetero e autocompreensão do círculo hermenêutico. Este outro é o que interpela o sujeito desde a natureza, o ambiente, e os outros humanos e não-humanos com quem compartilhamos nossos saberes e incertezas do mundo - sem esquecer o outro 
de nós, o inconsciente ou a "outra cena" que dissolve a hegemonia de uma razão plena de si. Assim, podemos encontrar no pensamento hermenêutico de Gadamer e na fenomenologia de Merleau-Ponty a expansão da noção de verdade, para além da perspectiva racionalista cartesiana e kantiana que acompanha a crítica ao reducionismo iluminista da autoconsciência determinada e seu controle sobre o mundo. Esses conceitos põem em ação o pressuposto de uma fronteira indistinta entre sujeito e ambiente, na medida em que buscam desconstruir as dualidades interno/externo e sujeito/ambiente, na direção do que poderíamos chamar de uma epistemologia compreensiva, cuja orientação ecológica evidencia-se no reconhecimento das relações simétricas com o ambiente, bem como da atividade do ambiente (nãohumano) nesta relação.

"Paisagens da compreensão" alude, portanto, aos caminhos da compreensão desde um modo de conhecer (algo, alguém e a si mesmo) não objetificador, que implica um lançar-se, um jogar o jogo. Este é também o modo de ser interpelado pela obra de arte. $\mathrm{O}$ jogo, a arte, a paisagem e o encontro social (com os outros humanos) remetem à aventura da compreensão e da autocompreensão que supõe um sujeito implicado na relação de conhecimento, recusando a idéia cartesiana de um sujeito da razão, observador, situado em algum lugar fora do mundo. A noção de paisagem que aqui trazemos compartilha da perspectiva do engajamento no mundo (Ingold, 2000) e deixa de ser o pano de fundo onde a ação acontece para ser, ela mesma, um feixe de ações articuladoras do encontro humano e não-humano, ou ainda uma trama - no sentido da tecelagem e do drama - deste encontro como mútua inscrição das marcas humanas no ambiente e deste na experiência humana do mundo.

Nesta direção, interessa-nos, sobretudo, pensar uma educação ambiental compreensiva desde a dimensão do engajamento como pertencimento ao mundo, em contraponto à externalidade que configura o mundo como objeto de um sujeito fora dele. Assim, nos tópicos que seguem destacamos o caráter do jogo e da obra de arte como modelos da compreensão, apontando o jogo como modo de ser da arte que nos faz ver que a dicotomia sujeito/objeto não é a única nem a maneira mais fundamental de compreender a existência humana. Do modelo do jogo, passamos à noção de paisagem e ao diálogo com 
Paisagens da compreensão: contribuiçôes da hermenêutica e da fenomenologia...

Merleau-Ponty e seu conceito de "corpo do mundo", para pensar no sujeito humano que está não apenas situado numa certa paisagem, mas esta é a condição de seu engajamento no mundo e na cultura. Na busca de dar voz às paisagens da vida e da compreensão que emergem de uma experiência de educação ambiental, convidamos o leitor aos caminhos de uma experiência dialógica que convida ao mergulho numa pesquisa-ação e a lançar-se na aventura da compreensão do outro, do ambiente, e da autocompreensão dos nossos referentes conceituais como educadores e pesquisadores.

\section{Hermenêutica: a arte da compreensão e a compreensão como arte}

Ao invés de dar crédito a Descartes, que tomava a autoconsciência como fundamento único de todo conhecimento sobre a realidade, Gadamer enfatiza a natureza dialógica não só da filosofia, mas da existência humana. Aquilo que somos depende muito dos que estão a nossa volta - o(s) outro(s). Antes que uma determinação de uma consciência livre possa escolher, somos fruto da tradição de sentido na qual estamos inseridos. Em My philosophical journey, Gadamer (1997) se autodefine como um filósofo que vivenciou todo o século XX com a preocupação de desenvolver as possibilidades de engajamento no "diálogo que somos todos nós" (Johnson, 2000, p. 19). A preocupação quase obsessiva do Iluminismo com a autoconsciência acabou por nos afastar de experiências que nos permitam compreender melhor a nossa existência. Johnson (2000) observa que o projeto de uma autoconsciência separou o sujeito e o objeto e restringiu a verdade ao domínio exclusivamente científico. Criticando esta tradição, Gadamer afirma que existem outras experiências de verdade - como a história e a arte - que são extracientíficas. A compreensão da arte e da história nos ajuda em nossa autocompreensão. "Gadamer acredita que nós somos alienados porque nosso conceito sobre o que é ser um ser humano não corresponde com nossa experiência vivida como humanos" (Johnson, 2000, p. 17).

A experiência da história e a experiência da arte fornecem os primeiros insights de Gadamer sobre como vencer a alienação estética contemporânea. A experiência da arte ocupa toda a primeira parte de Verdade e método. Para vencer a alienação contemporânea, Gadamer mergulha fundo na tradição estética anterior ao cartesianismo, principalmente em Platão, e assegura que há uma herança que precisa ser reconhecida no 
uso contemporâneo do conceito de estética. De acordo com Gadamer (2002), o conceito contemporâneo de consciência estética ainda está muito influenciado por Kant, que não concedia à experiência da arte o estatuto de verdade. A arte proporcionaria um prazer desinteressado, mas não um novo conhecimento. O próprio museu é visto por Gadamer com certa desconfiança, pois separa o trabalho artístico da vida cotidiana e, ainda por cima, é visto como atemporal. Nesse sentido, o museu corrobora a visão kantiana de que a obra de arte serve apenas para provocar o prazer da fruição estética. No entanto, se a ciência pode reservar o conceito de verdade para si, por que a experiência da arte não pode fazer o mesmo, pergunta Gadamer (2002). A pesquisa sobre a experiência da arte em períodos anteriores a Descartes e ao Iluminismo que se seguiu é particularmente reveladora de como as pessoas se relacionavam com seus trabalhos artísticos. "Elas viviam com eles e os compreendiam" (Johnson, 2000, p. 19); "Gadamer descreve a experiência da arte como um encontro com o mundo" (idem, ibid.). Ele afirma que essa experiência da verdade - de encontrar o mundo - pode ser até diferente daquela proporcionada pelas ciências naturais, mas certamente não é inferior, ou seja, a experiência da arte também contém verdade, e esta verdade é capaz de nos levar a autocompreensão. A arte, portanto, não é apenas prazer subjetivo, como pensava Kant, mas nos oferece uma compreensão.

O conceito de jogo clarifica bem essa situação de pertença, pois elimina as rígidas fronteiras entre sujeito e objeto traçadas pelo Iluminismo. O jogo é o modo de ser da arte e é um modo de compreensão que nos faz ver que a dicotomia sujeito/objeto não é a única nem a maneira mais fundamental de compreender a existência humana (Johnson, 2000). Uma reabilitação da arte para e pelo mundo da vida envolve uma transformação da nossa maneira de ver e de nos relacionar com a natureza. Johnson (op. cit., p. 23) afirma que Gadamer

(...) usa a experiência da arte para nos mostrar alguma coisa sobre nós mesmos. Nós não estamos alienados do mundo de nossa experiência. Nós pertencemos ao mundo de um modo integral. Mesmo como espectador do jogo que é parte do evento nós somos parte do mundo de nossa experiência. Assim como um espectador não pode controlar o jogo, nós não estamos no controle do mundo.

O mesmo pode ser dito de nossa relação com o ambiente: nós não podemos ou não deveríamos tentar controlá-lo. O ambiente faz parte do mundo de nossa experiência. 
Paisagens da compreensão: contribuiçôes da hermenêutica e da fenomenologia...

Gadamer não desenvolve uma estética, mas sim especula sobre a experiência da arte, mais especificamente sobre o modo de ser da obra de arte. A experiência da arte se mantém como uma oposição à teoria estética subjetivista. $\mathrm{O}$ jogo entre o intérprete e a obra não é limitado a um ser-para-si-mesmo da subjetividade. Ao contrário, o movimento de jogar não traz consigo um fim determinado. Existe um primado do jogo sobre a consciência do jogador. O jogo apenas "acontece" e, além disso, não tem propósito ou meta e nem sequer esforço. Esse "acontecer" do jogo ficou impossibilitado a partir da distinção cartesiana entre sujeito e objeto e o subjetivismo estético de Kant. Entretanto, com Gadamer essa situação muda. Ao invés de jogar autoconscientemente, a subjetividade é jogada. Há um caráter de autoesquecimento no jogo. O jogo é sempre um risco à autoconsciência determinada. Em um jogo nós podemos ser abordados e mudar, abordados por obras de arte, mas também por paisagens e ambientes. Gadamer (2002) diz que a grande ironia da relação entre o belo e a natureza é que esta última adquire seu status na filosofia moderna, justamente quando passa a ser considerada por Kant e pelos neokantianos como um mero reflexo da mente. $\mathrm{O}$ conceito gadameriano de jogo põe fim a essa situação.

Jünger (citado em Gadamer, 2002) diz que cada jogo tem seu próprio espírito. A natureza do jogo consiste em ser jogado, em "acontecer”. O modo de ser de um jogo é a autoapresentação e esta é definida por Gadamer (2002) como sendo uma característica ontológica universal da natureza. Contudo, o jogador, como já foi dito, não depende da autoconsciência, mas sim de ser trazido para dentro do domínio do jogo. $\mathrm{O}$ jogador experimenta o jogo como algo que o ultrapassa.

\section{A paisagem como engajamento compreensivo no ambiente}

O modelo do jogo supõe o engajamento num ambiente que transcende o ponto de vista particular do jogador. $\mathrm{O}$ jogo ultrapassa o jogador e, ao mesmo tempo em que o jogador faz o jogo, imprime-lhe ritmo, estilo, sem, contudo, dominar o curso dos acontecimentos. O jogador joga e é jogado. É neste ponto que poderíamos, seguindo este modelo compreensivo, mover-nos para outra noção particularmente interessante para nossos propósitos: a paisagem. ${ }^{2}$

Desde uma antropologia da paisagem, esta se apresenta como a própria condição de estar no mundo, onde se entrelaçam a cultura, a 
natureza e o sujeito (Lane, 2002; Hirsch, 2003; Low, 2006). Nos termos da antropologia ecológica de Ingold (2000), a paisagem é pensada como o horizonte de convergência dos corpos e organismos humanos e não-humanos com o ambiente que os engloba, distinguindo-se de uma concepção de paisagem como "vista" ou cenário para a ação humana. Para o autor, assim como os corpos não são formas dadas anteriormente, independentes dos seres que os constituem geneticamente, as paisagens não são cenários pré-existentes a espera das criaturas que vão ocupá-las (Ingold, op. cit.).

O conceito de paisagem como engajamento e mútua incorporação/apropriação, entre humanos e não-humanos, encontra um ponto de convergência produtivo na idéia de carne ou corpo do mundo, sugerida no último livro de Merleau-Ponty, "O visível e o invisível", onde destaca a continuidade entre o corpo/carne do mundo e o corpo/ carne humano:

Há um corpo da mente e uma mente do corpo (...). A noção essencial desta filosofia é a carne, que não é o corpo objetivo nem o corpo pensado pela alma (Descartes), [mas] o qual é o sensível no sentido daquele que é sentido e do que sente. (Merleau-Ponty, 1968, p. 259)

Para Merleau-Ponty, o mundo sustenta o corpo do sujeito e se move com ele, demarcando o seu campo da exploração perceptual e experiencial. Como condição corporal do sujeito, o mundo é experienciado como constitutivo do sujeito-corpo que o habita e não mais apenas como um referente externo e objetivo aos sujeitos que nele se movem. Nesse sentido, concordamos com Abram (1996, p. 85), quando este argumenta em favor do "nosso envolvimento inevitável naquilo que observamos, nossa imersão corporal nas profundezas de um corpo que respira e que é muito maior do que o nosso próprio corpo".

Com a noção de "carne", Merleau-Ponty inverte a posição cartesiana de um sujeito que pensa e, portanto, existe, ou, ainda, que pensa o mundo com uma mente à parte do mundo. Na perspectiva fenomenológica, o mundo pensa no sujeito que existe numa relação de continuidade e distinção com seu ambiente-mundo. O sujeito é parte orgânica da carne do mundo e sua singularidade nesta participação está na forma de exercer a reflexividade. Como afirma Merleau-Ponty (1968, p. 250), “a carne do mundo não sente a si mesma como minha 
Paisagens da compreensão: contribuiçôes da hermenêutica e da fenomenologia...

carne. Ela é sensível, mas não sensiente. Eu chamo isto de carne, no entanto, para dizer que isto não é absolutamente apenas um objeto”.

Esta configuração das relações sujeito-ambiente (ou ainda humano-natureza) evita tanto a fusão ou dissolução da singularidade humana no bios do mundo, quanto a arrogância que lança o humano para fora e acima do mundo das coisas e da natureza. Pode-se concluir, portanto, que o conceito de carne, de Merleau-Ponty, ao mesmo tempo em que estabelece uma continuidade entre o corpo humano e a carne do mundo, também mantém a alteridade entre estes pólos como constitutiva da experiência que se revela pela via ecológica do encontro do sujeito humano com a natureza. Esta mudança no olhar acaba produzindo uma ênfase no corpo ou na carne do mundo, que abarca de forma mais simétrica humanos e não-humanos, relativizando, de alguma maneira, os corpos dos indivíduos ou dos humanos como o elemento articular entre sujeito-objeto (Latour, 1994).

Desde esta reflexão poderíamos propor a noção de paisagem como unidade coerente do "visível", o campo de percepção de todos aqueles que a habitam e a constituem e por ela são constituídos; a totalidade dentro da qual todos os seres sensíveis estão inseridos. Seria possível, então, reconhecer no âmbito do conceito de paisagem uma dialética onde se distinguiria uma base material, a terra (land), e uma totalidade projetada e significada que transforma esta unidade física e material em paisagem (scape). Estabelece-se aí a tensão entre a experiência imediata e pré-objetiva no mundo (imediacy) e a sua objetivação na linguagem, num jogo de alteridade entre sujeito e objeto que se realiza dentro e fora de nós. Esta dialética, implicada no conceito de paisagem como engajamento no mundo, indica uma radical assunção da simetria e do pertencimento dos seres humanos e não-humanos à Terra, bem como de uma consequente atividade (agency) do ambiente.

Esta acepção de paisagem permite, assim, enfatizar a dinâmica dos processos temporais e sociais que dão forma ao ambiente, ao mesmo tempo em que constituem e modificam os lugares e os modos de habitar, permitindo distanciar-se de uma visão objetificadora que tende a atribuir um sentido de externalidade ao sujeito humano em relação ao mundo. Nesse sentido, pode-se compreender que a paisagem como lócus da relação do sujeito com o mundo - seus lugares, seus modos de ser, suas memórias e crenças - é constitutiva do seu ambiente 
de vida. A continuidade entre humanos e não-humanos se soma aos esforços de colapsar as dualidades natureza-cultura, mente-corpo, sujeito-objeto, interno-externo, conferindo um elemento de caráter ativo (agency) ao ambiente na sua relação com os seres que o habitam.

Entre saberes ribeirinhos e científicos: o jogo e a arte de lançar-se numa pesquisa-intervenção

Várias paisagens foram percorridas no encontro com as comunidades do Vale do Ribeira. Podemos começar pela seguinte: duas escolas, uma na região do Alto Ribeira, no Bairro da Serra município de Iporanga (SP), outra onde o Rio Ribeira encontra-se com o mar, a chamada Barra do Ribeira, em Iguape; nesta segunda escola, o trabalho se dava em parceria com uma associação de monitores ambientais. Na Ilha Comprida (SP), um grupo composto de agricultores e agricultoras residentes em Pedrinhas, um dos poucos bairros caiçaras que se mantém na ilha, também uma associação de extratores de plantas nativas, organizada pela prefeitura deste município - grupos heterogêneos com os quais foram desenvolvidas as experiências de pesquisa-intervenção em educação ambiental enfocadas aqui. Essas experiências se entreteciam em reflexões e elaborações de um grupo de pesquisadoras-educadoras ao desenvolver seus trabalhos de doutorado, mestrado e iniciação científica como projetos de pesquisa-intervenção com comunidades residentes no interior e entorno de unidades de conservação no Vale do Ribeira paulista, no período de 1999 a $2004 .^{3}$

Olhar para as experiências do grupo-pesquisador, sob a perspectiva da hermenêutica filosófica, permite identificar, na metodologia da pesquisa-intervenção desenvolvida, uma construção mútua dos sentidos da ação, da compreensão/interpretação do mundo e da experiência vivida e, ainda, dos sentidos da educação ambiental que pautava o trabalho. Sob essa perspectiva, na postura assumida está implícita, além da perda da segurança de uma consciência observadora e decodificadora de sentidos, uma recusa da dicotomia entre o plano do pensamento e da ação (Carvalho, 2008).

As paisagens configuradas nos encontros/confrontos comunicativos do grupo de pesquisa com moradores e moradoras do Vale do Ribeira estiveram também marcadas pelos conflitos entre conservação 
Paisagens da compreensão: contribuiçôes da hermenêutica e da fenomenologia...

ambiental e as experiências de vivência/trabalho daquela gente. Por concentrar os maiores remanescentes de mata atlântica do país, devido ao próprio histórico das políticas de desenvolvimento no estado de São Paulo, o Vale do Ribeira é uma região de grande interesse para o ambientalismo, configurando-se hoje num conjunto em que se sobrepõem várias categorias de unidades de conservação, resultado de um processo histórico de negociação entre movimento ambientalista e Estado.

"Depois que o meio ambiente chegou, nossa vida virou um inferno" 4 - este depoimento de um morador da região soma-se a muitos outros que revelam tanto um estranhamento como um descontentamento com a proposta de conservação para a área. $\mathrm{O}$ meio ambiente passou a ser compreendido como restrição, não como espaço de vivência e trabalho. Em um primeiro momento, a apresentação do grupo-pesquisador aos moradores e moradoras do Vale do Ribeira, como educadoras ambientais, era, muitas vezes, associada à ação normativa dos órgãos de fiscalização. Por outro lado, notava-se um descrédito que moradores e moradoras tinham em relação a pesquisadores e suas pesquisas, o que era explicitado na fala de alguns e no silencioso olhar desconfiado de outros. A crítica era feita à postura daqueles que "coletavam" conhecimentos e problemas dos que lá moravam, sem nada de volta oferecer. Quando retornavam, muitos vinham como uma extensão dos saberes de uma cultura científica a se impor sobre outros saberes.

Motivado pelas leituras de Boaventura de Sousa Santos (1999, 2001) e Eda Tassara (1996), o grupo-pesquisador relacionava as experiências no Vale do Ribeira com a idéia de expansão de um conceito de ambiente, elaborado num contexto técnico-científico, sobrepondose a outros possíveis entendimentos construídos pelas comunidades residentes há gerações naquelas áreas. $\mathrm{O}$ trabalho do grupo-pesquisador partiu da compreensão de que, subjacente à imposição cultural, está presente uma imposição epistemológica, em que os saberes construídos num contexto histórico-cultural - o científico - colocam-se como verdadeiros, silenciando outras formas de interpretar a realidade.

Um pressuposto inicial para a educação ambiental que se buscava construir na experiência da pesquisa-intervenção foi sua fundamentação em relações dialógicas, em que a compreensão do mundo e a construção de veredas para uma vida sustentável naquelas localidades se dessem não de uma perspectiva explicativa, mas através de encontros 
de interpretações sobre realidades e temáticas em foco. Da relação recursiva entre compreensão e prática, enraizada em aspectos culturais e históricos, ampliava-se a noção de educação ambiental para uma postura compreensiva que se constrói na imprevisibilidade do encontro.

A proposição de Gadamer sobre diálogo contribui para compreender a trajetória experienciada pelo grupo-pesquisador e para os sentidos que projetava sobre sua ação junto aos grupos do Vale do Ribeira. Na perspectiva gadameriana, o diálogo permite acessar um conhecimento que até então não estava disponível, que será tecido nos olhares que se entrecruzam e se expressam através da linguagem. $\mathrm{O}$ diálogo é aquilo que nos deixou uma marca, que permitiu que viesse ao nosso encontro algo que não havíamos acessado em nossa experiência própria do mundo (Gadamer, 2000).

A compreensão não pressupõe que estejamos de acordo com tudo que nos chega através do distante, do outro, do passado. Ela habita justamente essa zona de tensão entre o próprio e o alheio. O outro - pessoa, texto, obra de arte, natureza - vem ao nosso encontro e solicita-nos. Traz algo de estranho, reserva uma distância e assim desestabiliza, provoca perguntas. O encontro com o outro, com o distante, pressupõe a saída de si para partilhar essa instância de desequilíbrio (Flickinger, 2000). A distância da alteridade solicitanos, levando-nos a colocar em questão nossos pressupostos, certezas. Passamos então a reconhecer o estranho naquilo que é próprio, procurando uma re-familiarização (Hermann, 2003).

Como se deu, no desenrolar das experiências do grupo-pesquisador, este movimento de estranhamento e familiarização? O "outro" - fosse este a colega do grupo de pesquisa, as paisagens do Vale do Ribeira, a leitura do mundo 5 de seus moradores e moradoras com as demandas próprias de cada localidade - representou, ao mesmo tempo, o estranho a desfamiliarizar as certezas, mas também a "possibilidade de construir uma coisa que jamais imaginaria que seria possível a [sua] existência sozinha". ${ }^{6}$ A rítmica quinzenal dos encontros do grupo-pesquisador, o ir e vir entre o individual e o coletivo, foi importante constituinte das experiências de pesquisa que ali se desenvolveram. O acontecer dinâmico constituía-se também como sujeito do processo a movimentar a rítmica do fazer-e-refazer do grupo-pesquisador, semelhante ao exposto anteriormente sobre o jogo como sujeito na relação com o jogador. 
Paisagens da compreensão: contribuiçôes da hermenêutica e da fenomenologia...

A trajetória de construção dos referenciais teórico-metodológicos esteve marcada por este movimento, visto aqui como inserido no círculo hermenêutico de compreensão. Tal círculo consiste em considerar a historicidade atuando no processo de compreensão e, portanto, levar em conta os pressupostos e pré-conceitos que o sujeito projeta ao buscar compreender a situação em que está inserido. Esta pré-compreensão pode ser modificada no processo da experiência, à medida que se busca a consciência hermenêutica, cujo propósito não é confirmar as antecipações, mas iluminar os pré-conceitos que orientam a compreensão. Assim, o projeto está sempre sujeito a um redesenho que resulte em um aprofundamento de sentido. Cada revisão do projeto pode abarcar um novo projeto de sentido (Gadamer, 1994).

De início, em torno de um objetivo traçado para o trabalho no Vale do Ribeira, a partir do projeto temático "Floresta \& Mar", confluíram-se interesses e necessidades múltiplas das integrantes do grupo-pesquisador. Das leituras, discussões e idas ao Vale foi construída uma primeira proposta metodológica que orientaria as experiências de pesquisa-intervenção. Cada pesquisadora, ao colocar em movimento esta proposta com o grupo junto ao qual atuou - professores, professoras e monitores ambientais, agricultores e agricultoras, extratoras de samambaia -, foi re-elaborando o que foi traçado a priori. De volta ao coletivo, na partilha do vivenciado em campo, a proposta geral também recebia reformulaçóes, ampliando a compreensão do acontecer e mesmo re-elaborando os conceitos.

No processo de compreender esteve, portanto, implicado o questionamento. Ao acompanhar o fazer-pesquisa do grupo, é possível reconhecer um perguntar não para confirmar o que se sabia, mas para proporcionar a si mesmo e ao desconhecido um mostrar-se que o preserva e expõe simultaneamente. Os questionamentos elaborados pelo grupo-pesquisador eram movidos por este interrogar como abertura, como desconhecimento da resposta. A relação dialética entre pergunta e resposta foi permitindo desmobilizar certezas, expondo um desafio a ser enfrentado. Eram perguntas lançadas às teorias, a si mesmo, ao grupo-pesquisador, às proposições metodológicas dos autores que nos embasavam, mas não à busca de uma teoria estanque, em que as respostas são aceitas como válidas por sua legitimidade acadêmica. Tal postura conferia ao processo do grupo a dimensão de sua 
incompletude: o fio, que tecemos ontem, hoje se desfez, desfiou. As respostas não vinham diretas, mas na troca das experiências vividas. Nem sempre havia respostas a partilhar, mas perguntas para serem refletidas conjuntamente, no grupo-pesquisador e com os grupos do Vale do Ribeira.

Flickinger (1994, p. 205) argumenta que a abordagem hermenêutica para a questão ambiental leva-nos a "revincular as questões ambientais ao agir humano que as originou", defendendo ainda que tal revinculação "teria que recorrer à postura científica não mais objetificadora, portanto, não mais ao modelo de explicação causal de fatos". Uma educação ambiental dialógica, portanto, constrói-se a partir dos sentidos que assume o ambiente para moradores e moradoras no Vale do Ribeira e em outras localidades, considerando que esta relação é permeada pela linguagem e, portanto, pela história e pela cultura desses grupos. Em seu contexto/horizonte, quais são os sentidos que a realidade assume, como a nomeiam? Nesta concepção, dialogar sobre o ambiental é considerá-lo inserido na história e linguagem, no processo dinâmico de instauração de sentidos e de revisão dos mesmos. Nesta compreensão da educação ambiental, portanto, poderíamos reivindicar a acepção de paisagem conforme proposta neste texto: o ambiente não é visto como objeto externo ao sujeito humano que o compõe. $\mathrm{O}$ ambiente se constitui também pelo modo de ser desse sujeito, por suas memórias, crenças, ou seja, pela dinâmica dos processos temporais e sociais.

Nos projetos de conservação que chegam como imposição de um conceito de ambiente elaborado na esfera técnico-científica, permanece um estranhamento que não parece solicitar aqueles moradores e moradoras à nova compreensão, pois não se abrem a dialogar com os sentidos já projetados ao seu espaço de vivência e de trabalho. Sendo assim, "meio ambiente" permanece associado ao órgão de fiscalização, ao controle e à coerção de suas práticas locais.

Os sentidos do ambiental são, ao mesmo tempo, pontos de partida e de chegada de um trabalho educativo conduzido na perspectiva aqui apresentada, uma vez que serão configurados pelo processo de compreensão, que implica considerar a história agindo sobre a construção dos conceitos e a ação pondo-os em risco no processo de abertura ao outro que desestabiliza o que é familiar. 
Paisagens da compreensão: contribuiçôes da hermenêutica e da fenomenologia...

\section{A textura da paisagem: em direção a uma educação ambiental compreensiva}

A narrativa desta experiência não apenas interpreta uma paisagem, ao mesmo tempo geográfica, humana e simbólica, evidenciando as diferentes compreensões do ambiental, mas, ao lançar-se na busca de um diálogo autêntico, passa a constitui-la. As metáforas aqui evocadas trazem duas dimensões reveladoras: "têxtil" e "textura". O têxtil está no novelo e na novela com que se tece a intriga, no sentido grego retomado por Ricouer (1994), em Tempo e narrativa. Isto é, a arte de dar sentido ao imprevisível do destino, narrar, encadear os acontecimentos, entretecer o arbitrário com o amálgama de uma intencionalidade ao mesmo tempo inextricável e apenas uma, entre tantas ligas possíveis, para encadear o fluxo da ação humana. A narrativa é polifônica. Falam as vozes da comunidade do Vale, os moradores, as vidas do local, e falam as vozes do grupo-pesquisador.

Por outro lado, a textura também está presente aqui como o que não se exaure na textualidade, mas remete à condição de dobra, ruga, sulco, fissura, talvez como produção de uma ambiência (Rego, 2000), que é fruto de um feixe de ações interconectadas: a ação do tempo humano e geológico, das marcas humanas e da "geo-grafia" como ato de marcar a terra (Porto Gonçalves, 2001) e, podemos acrescentar, ser por ela marcado. Neste jogo de diferentes escalas de tempos e espaços negociados, desenha-se a paisagem como lugar material e simbólico onde os modos de vida e a vida do ambiente se encontram em recíproca acomodação/negociação.

E o que dizer de uma educação ambiental que se pauta por uma postura compreensiva? Sem qualquer pretensão de defini-la, talvez pudéssemos sugeri-la como uma postura educativa que se desapega das certezas e abre mão do que a psicanálise lacaniana descreveu como "a posição do mestre”. Ou seja, aquela posição em que alguém (o analista ou, no nosso caso, o educador) assume o suposto saber que lhe é atribuído sem destituir-se deste lugar, obturando a emergência do sujeito no outro. Ao invés desta posição assegurada pela crença no poder explicativo, a compreensão hermenêutica aposta numa atenta disposição de conhecer, assumindo a imprevisibilidade do encontro, os riscos do jogo, a primazia da pergunta sobre a resposta, desde uma relação de pertencimento com o que se dá a conhecer. Talvez soe demasiado 
romântico para um mundo competitivo e veloz que cultua a intervenção e disputa a direção das mudanças. Contudo, considerando as raízes românticas da hermenêutica e da própria educação ambiental, poderíamos dizer que uma educação compreensiva compartilharia, em certa medida, de uma posição anti-iluminista e, portanto, crítica de uma razão triunfante e objetificadora que caracteriza a ciência moderna. Uma educação compreensiva assumiria, assim, em contraponto com as ambiçôes de domínio do real, uma atitude de prudência epistemológica, seguindo na mesma direção do que Santos (2002) chamou de uma ciência modesta.

\section{Recebido em janeiro de 2008 e aprovado em outubro de 2008.}

\section{Notas}

1. Para nossa reflexão cabe alertar que tomamos a noção de mundo indistintamente à de ambiente no seu sentido de um ambiente-mundo.

2. A noção de paisagem, desde um modelo do engajamento e da corporeidade, pode ser encontrada também em uma antropologia da paisagem que fala em espaços incorporados (embodied spaces) (Lown \& Lawrence-Zúniga, 2006) ou paisagens incorporadas (embodied landscapes) (Ingold, 2000).

3. O grupo-pesquisador foi composto por Alessandra Buonavoglia Costa-Pinto, Alik Wunder, Caroline Ladeira de Oliveira, Érica Speglich, Kellen Junqueira, Maria Rita Avanzi, Rita de Cássia Nonato, Shaula Maíra Sampaio, Susana Oliveira Dias, Vivian Gladys de Oliveira. Corresponde ao componente Intervenções e educação ambiental do projeto temático "Floresta \& Mar: usos e conflitos no Vale do Ribeira e Litoral Sul", desenvolvido no NEPAM-UNICAMP. A expressão grupo-pesquisador provém da sociopoética, proposta de pesquisa criada por Jacques Gauthier, que foca o processo grupal de produção de conhecimento.

4. Depoimento de morador da Vila Itinguçu, município de Peruíbe, entorno da Estação Ecológica Juréia Itatins, em abril de 1999.

5. O conceito freireano de leitura do mundo procura abarcar a interpretação que o educando faz de sua realidade, a qual precede a leitura da palavra (Freire, 1989).

6. Caroline Ladeira de Oliveira (integrante do grupo-pesquisador), depoimento em 25/05/ 2001 .

\section{Referências}

ABRAM, D. Merleau-Ponty and the voice of the Earth. In: Macauley, D. (Ed.). Minding nature: the philosophers of ecology. New York: Guildford, 1996. 
Paisagens da compreensão: contribuições da hermenêutica e da fenomenologia...

CARVALHO, I.C.M. A invenção ecológica: narrativas e trajetórias em educação ambiental no Brasil. 3. ed. Porto Alegre: UFRGS, 2008 .

FLICKINGER, H-G. O ambiente epistemológico da educação ambiental. Educação \& Realidade, Porto Alegre, v. 19, n. 2, p. 197-207, jul./dez. 1994.

FLICKINGER, H-G. Da hermenêutica da arte à hermenêutica filosófica. In: Almeida, C.L.; Flickinger, H.-G.; Rohden. L. Hermenêutica filosófica: nas trilhas de Hans-Georg Gadamer. Porto Alegre: EDIPUCRS, 2000 .

FREIRE, P. A importância do ato de ler em três artigos que se completam. 23. ed. São Paulo: Cortez, 1989.

GADAMER, H-G. Verdad y método. Salamanca: Sígueme, 1994. v. 2.

GADAMER, H.-G. Reflections on my philosophical journey. In: Hahn, E. The philosophy of Hans-Georg Gadamer. Chicago: Open Court, 1997.

GADAMER, H.-G. A incapacidade para o diálogo In: AlmeIDA, C.L.; Flickinger, H.-G.; Rohden, L. Hermenêutica filosófica: nas trilhas de Hans-Georg Gadamer. Porto Alegre: EDIPUCRs, 2000.

GADAMER, H.-G. Verdade e método: traços fundamentais de uma hermenêutica filosófica. 4. ed. Petrópolis: Vozes, 2002.

HERMANN, N. Hermenêutica e educação. Rio de Janeiro: DP\&A, 2003.

HIRSCH, E.; O'HALON, M. The anthropology of landscape: perspectives on place and space. Oxford: Clarendon, 2003.

INGOLD, T. The perception of the environment: essays in livelihood, dwelling and skill. London: Routledge, 2000.

JOHNSON, P.A. On Gadamer. Belmont: Wadsworth, 2000.

LANE, B.C. Landscapes of the sacred: geography and narrative in American spirituality. Baltimore: Johns Hopkins University, 2002. 
LATOUR, B. Jamais fomos modernos: ensaio de antropologia simétrica. Rio de Janeiro: Editora 34, 1994.

LOW, S.M.; LAWRENCE-ZÚNIGA, D. The anthropology of space and place. Malden: Blackwell, 2006.

MERLEAU-PONTY, M. Phenomenology of perception. Evanston: Northwestern University, 1962.

MERLEAU-PONTY, M. The visible and the invisible. Evanston: Northwestern University, 1968.

PORTO-GONÇALVES, C.W. Geo-grafias; movimientos sociales, nuevas territorialidades y sustentabilidad. Mexico, DF: Siglo Veintiuno, 2001.

REGO, N. Apresentando um pouco do que sejam ambiências e suas relações com a geografia e a educação In: Rego, N.; Suertegaray, D.; Heidrich, A. Geografia e educação: geração de ambiências. Porto Alegre: UFRGS, 2000.

RICOUER, P. Tempo e narrativa. Campinas: Papirus, 1994.

SANTOS, B.S. Pela mão de Alice: o social e o político na pósmodernidade. São Paulo: Cortez, 1999.

SANTOS, B.S. A crítica da razão indolente: contra o desperdício da experiência. In: Santos, B.S. Para um novo senso comum: a ciência, o direito e a política na transição paradigmática. São Paulo: Cortez, 2001. v. 1.

SANTOS, B.S. Um discurso sobre as ciências. 13. ed. Porto: Afrontamento, 2002.

TASSARA, E.T.O. Intervenção social e conhecimento científico: questões de método na pesquisa social contemporânea. In: SIMPÓSIO DE PESQUISA E INTERCÂMBIO CIENTÍFICO DA ANPEPP, 6., 1996, Teresópolis. 